\title{
A Escuta do Masculino na Clínica Psicanalítica Contemporânea: Singularidades de um Padecer ${ }^{1}$
}

\author{
Fernanda Cesa Ferreira da Silva \\ Mônica Medeiros Kother Macedo ${ }^{2}$ \\ Pontificia Universidade Católica do Rio Grande do Sul
}

\begin{abstract}
RESUMO - Este estudo aborda as especificidades de padecimento psíquico masculino no espaço da clínica psicanalítica contemporânea. Foram entrevistados 10 psicanalistas e os dados obtidos foram analisados qualitativamente por meio da técnica de Análise de Conteúdo. Foi possível explorar os efeitos que as demandas contemporâneas produzem nos campos intrapsíquico e intersubjetivo, viabilizando a compreensão de padecimentos masculinos atuais. Foram também aprofundados conceitos relativos ao trabalho analítico, reconhecendo na Psicanálise um recurso ético e vigente na clínica contemporânea do masculino. A escuta analítica como exercício ético, ao situar-se na contramão das imposições contemporâneas, dá espaço para um trabalho com a singularidade do sujeito.
\end{abstract}

Palavras-chave: masculinidade, psicanálise, contemporaneidade, clínica psicanalítica.

\section{Male Listening in Contemporary Psychoanalytical Practice: Singularities of suffering}

\begin{abstract}
This paper addresses the particularities of male psychic suffering in contemporary psychoanalytical practice. Ten psychoanalysts were interviewed and the obtained data were qualitatively analyzed using content analysis. The effects that contemporary demands cause in the intrapsychic and intersubjective field were explored, enabling to comprehend current male suffering. The concepts related to psychoanalytical work were also explored, recognizing in Psychoanalysis an ethical and current resource in contemporary practice of male subjects. Analytical listening as an ethical endeavor, which is going in the opposite direction of contemporary demands, gives the opportunity to work with the singularity of the subject.
\end{abstract}

Keywords: masculine, psychoanalysis, contemporary psychoanalytical practice.

O sujeito contemporâneo, inserido em uma dinâmica de convívio marcada por instabilidades, pela vigência do efêmero, do fragmentário, do caótico, depara-se com novas demandas psíquicas, políticas e sociais. Estas diversidades evidenciam-se por meio de indagações a respeito das modalidades de ser e estar no mundo (Dockhorn \& Macedo, 2008; Staudt, 2007). Os papéis sociais, políticos e culturais desempenhados pelo indivíduo estão em contínuo processo de reconstrução, incluindo-se, portanto, nesse contexto, relevantes reflexões a respeito do papel masculino na contemporaneidade.

No cenário atual constata-se que o homem está atravessando uma "crise da masculinidade" (Machado, 2008; Cecarelli, 1998). Se, antigamente, a masculinidade era caracterizada por poder, força e virilidade, hoje em dia são diversas as definições que se cruzam para dar conta do que é ser homem. Conforme Araújo (2005), as mudanças provocadas pelo feminismo desestabilizaram o modelo masculino tradicional e impuseram a necessidade de sua revisão. Assim sendo, percebe-se o surgimento de tensões entre os padrões

1 Este estudo foi desenvolvido a partir de uma Dissertação de Mestrado, a qual contou com uma bolsa de fomento do CNPq.

2 Endereço para correspondência: Av. Ipiranga, 6681 - Prédio 11/ sala 926, Bairro Partenon. Porto Alegre, RS. CEP 90619-900. E-mail:monicakm@pucrs.br tradicionais da identidade masculina e a possibilidade de se viver novas formas de ser homem na cultura ocidental.

Em conseqüência da ausência de preparação para essa mudança, o sujeito, muitas vezes, pode vivenciar um estado de "atordoamento" frente às dicotomias das demandas às quais é convocado a, rapidamente, atender. Tais constatações permitem afirmar a necessidade e a relevância de estudos relacionados às modalidades de padecimento psíquico masculino próprias desta época.

$\mathrm{Na}$ abordagem da subjetividade humana, a Psicanálise se apresenta como um valioso recurso de leitura tanto do processo de subjetivação quanto da dinâmica dos padecimentos psíquicos. A Psicanálise, que nasce a partir das inquietações de Sigmund Freud na clínica da histeria, enquanto teoria, método e técnica que se propõe a pensar o humano e as especificidades psíquicas, não pode se furtar a lançar seu olhar em relação às modalidades contemporâneas de padecimento no cenário da masculinidade.

Este estudo tem, portanto, o objetivo de compreender as configurações de padecimento psíquico masculino que se fazem presentes na clínica psicanalítica contemporânea. Para tal, buscou-se entrevistar psicanalistas os quais, a partir da escuta de demandas e padecimentos masculinos, permitissem realizar reflexões a respeito desta especificidade de prática clínica com homens. 


\section{Método}

\section{Participantes}

Participaram do estudo 10 psicanalistas, localizados por conveniência, independentemente da instituição formadora, com experiência de um período mínimo de 10 anos de prática clínica. A idade média dos participantes é de 54,3 anos, com uma média de tempo de graduação de 30,1 anos e tempo médio de exercício da clínica psicanalítica de 27,3 anos. Cinco dos participantes são do sexo masculino e cinco são do sexo feminino, sendo destes, quatro médicos psiquiatras e seis psicólogos.

\section{Procedimentos}

Após aprovação do Projeto de Pesquisa pelo Comitê de Ética em Pesquisa da Universidade foram contatados os psicanalistas por indicação de seus pares. No contato pessoal inicial, após serem esclarecidos os objetivos e procedimentos da investigação e tendo obtida a concordância em participar, foram marcadas as entrevistas. Todos os participantes assinaram o Termo de Consentimento Livre e Esclarecido, bem como participaram individualmente de uma entrevista semiestruturada de questões abertas, na qual foram contemplados os seguintes tópicos: (1) particularidades que levam um homem a buscar atendimento psicanalítico; (2) demandas psíquicas apresentadas por pacientes homens em relação com o contexto contemporâneo; (3) relação entre o papel masculino e o sofrimento psíquico; (4) singularidade das configurações de padecimentos psíquicos de pacientes masculinos sob o olhar da Psicanálise e (5) interrogações teóricas e técnicas oriundas da escuta psicanalítica de pacientes masculinos. As entrevistas foram gravadas em áudio após a devida autorização do participante e, posteriormente, transcritas. A análise destas permitiu a identificação de conteúdos que foram codificados em categorias de respostas por meio da técnica de Análise de Conteúdo desenvolvida por Bardin (1991).

\section{Resultados e Discussão}

Após a leitura do material obtido nas dez entrevistas, foram definidas as unidades de significado, as quais, por sua vez, foram organizadas em categorias iniciais. A descrição de cada categoria final (ver Tabela 1) foi estruturada a partir das categorias intermediárias que lhe deram origem e, com a finalidade de proporcionar rigor e validade às categorias, foram transcritas, de forma fiel, algumas verbalizações dos participantes entrevistados.

A primeira categoria final foi nomeada "Demandas da contemporaneidade: efeitos no campo intersubjetivo". A diversidade presente nas relações interpessoais, principalmente nas relações familiares, é um dos marcos da contemporaneidade. Fatores, como gênero, transgeracionalidade, a coexistência de antigos padrões junto às novas demandas relacionais, compõem a singular construção dos papéis contemporâneos (Staudt, 2007). Nesta perspectiva, o Participante 9 contata a presença de dúvidas masculinas em seu exercício clínico: "Tem uma insegurança em relação a todas essas demandas sociais que se vêem obrigados a responder. Tem uma certa confusão, pode até ter um certo saudosismo, de dizer que era muito melhor antigamente que tudo era definido. Mulher cuidava da casa, homem cuidava de ganhar dinheiro, os filhos somente obedeciam. Quer dizer: como é que eu vou agir diante desta nova ordem? A sociedade me exige tanta coisa, mas eu posso também ocasionalmente estar desempregado e a mulher estar sustentado a casa. Eu posso aceitar isso? Eu não posso?" (P9).

Para a compreensão dos novos tempos, é necessário mencionar as transformações que se fizeram presentes na dinâmica das relações interpessoais. Jerusalinsky (2007) considera que a diferença sexual, partindo do campo da anatomia, desdobrou-se em uma diferença simbólica, representada pela detenção do falo. Os homens seriam o sexo forte, possuidores do falo, e as mulheres o sexo débil, consideradas castradas; porém, a partir do século XX, foi registrado o divórcio entre a anatomia e a condição fálica, separando o pênis do falo, passando o último a assumir múltiplas formas de representação. Cabe destacar as relevantes mudanças que ocorreram no desempenho e nas atribuições dos papéis masculino e feminino, bem como suas repercussões no cenário das relações. Ressalta-se, entre tais mudanças, o afrouxamento do patriarcado (Machado, 2008; Jerusalinsky, 2007; Araújo, 2005) e o movimento feminista. Sobre esta constatação os entrevistados manifestam:"No século 19 uma mulher tinha que ser bonita, se preparar para o amor e para uma vida de casada, ela era muito poderosa naquele domínio doméstico. E os homens eram reis absolutos. Já, no século 20 o ideário feminino se modificou e as mulheres começaram a querer ter outro papel. Os homens, então, começaram a se enfrentar muito com a questão de que as mulheres passaram a não ser tão satisfeitas com eles quanto eram antes, quando eram reis absolutos" (P8). "Os homens, em função das mulheres estarem trabalhando fora, tem que pegar mais junto na casa (...) essas demandas que os homens não tinham, eles passaram a ter também. E agora, os homens também estão sofrendo com essa dupla jornada. É uma configuração familiar diferente, em que os papéis se mesclam mais" (P10).

A partir das falas dos entrevistados, é possível constatar uma comparação entre os gêneros para ilustrar tanto questões masculinas quanto femininas. Siqueira (1997) e Araújo (2005) referem a impossibilidade de problematizar o feminino e o masculino no singular, considerando que a constituição da identidade de gênero caracteriza-se por um processo relacional. No presente estudo, os entrevistados eram convidados a discorrer a respeito das temáticas referentes à masculinidade; entretanto, os temas femininos eram constantemente trazidos à tona, denotando a dificuldade em compreender um gênero dissociado do outro.

Dessa forma, torna-se indispensável citar as progressivas mudanças do papel feminino nas últimas décadas e o decorrente reflexo dessas no papel masculino, bem como abordar a importância desta inter-relação no contexto atual. Nessa direção, Araújo (2005) reforça a importância do capitalismo que, na sua evolução, enfraqueceu o patriarcado, pois, para 
Tabela 1. Categorização Inicial, Intermediária e Final dos dados obtidos nas dez entrevistas com os participantes do estudo.

\begin{tabular}{|c|c|c|}
\hline Categorias Iniciais & Categorias Intermediárias & Categorias Finais \\
\hline Modificações e especificidades do papel feminino & \multirow{4}{*}{$\begin{array}{l}\text { Transformações e especificidades } \\
\text { do papel masculino e do papel } \\
\text { feminino e seus efeitos nas relações } \\
\text { interpessoais }\end{array}$} & \multirow{9}{*}{$\begin{array}{l}\text { Demandas da contem- } \\
\text { poraneidade: efeitos no } \\
\text { campo intersubjetivo }\end{array}$} \\
\hline Modificações e especificidades do papel masculino & & \\
\hline Descompasso entre homens e mulheres & & \\
\hline $\begin{array}{l}\text { Comparação com as especificidades femininas para explicar as } \\
\text { questões masculinas }\end{array}$ & & \\
\hline Contemporaneidade marcada pela imposição de padrões & \multirow{3}{*}{$\begin{array}{l}\text { Aspectos da contemporaneidade no } \\
\text { cenário de excessos }\end{array}$} & \\
\hline $\begin{array}{l}\text { Contemporaneidade marcada pela prioridade da individualidade } \\
\text { em detrimento da alteridade }\end{array}$ & & \\
\hline Contemporaneidade marcada pela não-castração do sujeito & & \\
\hline $\begin{array}{l}\text { Contemporaneidade marcada por uma maior igualdade entre os } \\
\text { sexos }\end{array}$ & \multirow{2}{*}{$\begin{array}{l}\text { Avanços e conquistas decorrentes } \\
\text { da contemporaneidade }\end{array}$} & \\
\hline Flexibilização de papéis nas novas configurações familiares & & \\
\hline Insegurança masculina frente à mudança de paradigmas & \multirow{9}{*}{$\begin{array}{l}\text { Efeitos psíquicos na identidade } \\
\text { masculina decorrentes das trans- } \\
\text { formações contemporâneas }\end{array}$} & \multirow{17}{*}{$\begin{array}{l}\text { O padecimento masculino } \\
\text { contemporâneo: a história } \\
\text { de Narciso no cenário de } \\
\text { excessos }\end{array}$} \\
\hline Desestabilização masculina frente ao novo papel da mulher & & \\
\hline $\begin{array}{l}\text { Criação pelo sujeito de um ideal masculino marcado pela vigência } \\
\text { da plenitude e da perfeição }\end{array}$ & & \\
\hline Falta da figura paterna como um modelo masculino a seguir & & \\
\hline $\begin{array}{l}\text { Prejuízo na intimidade e na capacidade de vincular-se afetiva- } \\
\text { mente }\end{array}$ & & \\
\hline $\begin{array}{l}\text { Problemáticas masculinas em relação à vida afetiva/amorosa e ao } \\
\text { exercício da paternidade }\end{array}$ & & \\
\hline $\begin{array}{l}\text { Problemáticas masculinas em relação à sexualidade, potência e } \\
\text { virilidade }\end{array}$ & & \\
\hline $\begin{array}{l}\text { Problemáticas masculinas contemporâneas relacionadas ao } \\
\text { narcisismo }\end{array}$ & & \\
\hline Importância do exercício laboral na identidade masculina & & \\
\hline Queixas relacionadas à depressão & \multirow{8}{*}{$\begin{array}{l}\text { Padecimentos intrapsíquicos no- } \\
\text { meados e identificados no cenário } \\
\text { masculino }\end{array}$} & \\
\hline Conflitivas no terreno da sexualidade & & \\
\hline Sentimento de desamparo & & \\
\hline Uso de drogas & & \\
\hline Angústia pela sensação de não atender os ideais sociais & & \\
\hline Angústia como propulsora para o tratamento & & \\
\hline $\begin{array}{l}\text { Demanda de análise como um trabalho de desvelamento do real } \\
\text { padecimento }\end{array}$ & & \\
\hline $\begin{array}{l}\text { Demanda de análise como um trabalho de descoberta do si } \\
\text { mesmo }\end{array}$ & & \\
\hline Qualidade da escuta psicanalítica & \multirow{10}{*}{$\begin{array}{l}\text { Necessidade de cuidado e manu- } \\
\text { tenção do potencial inovador e } \\
\text { criativo da Psicanálise }\end{array}$} & \multirow{10}{*}{$\begin{array}{l}\text { A vigência da Psicanálise } \\
\text { como recurso ético na } \\
\text { clínica contemporânea do } \\
\text { masculino }\end{array}$} \\
\hline $\begin{array}{l}\text { Analista considerando sua própria implicação na contemporanei- } \\
\text { dade }\end{array}$ & & \\
\hline $\begin{array}{l}\text { Especificidades do atendimento psicanalítico com pacientes } \\
\text { homens }\end{array}$ & & \\
\hline A transferência como recurso essencial do processo analítico & & \\
\hline $\begin{array}{l}\text { Necessidade de repensar a teoria psicanalítica para atender às } \\
\text { novas demandas }\end{array}$ & & \\
\hline Ampliação do acesso à Psicanálise & & \\
\hline Necessidade de flexibilização do setting analítico & & \\
\hline Transformações na busca por tratamento & & \\
\hline Psicanálise: prática clínica que constrói teoria & & \\
\hline $\begin{array}{l}\text { Espaço analítico situando-se na contramão das imposições da } \\
\text { contemporaneidade }\end{array}$ & & \\
\hline
\end{tabular}


atender tanto às necessidades do mercado de trabalho quanto as da própria família, a mulher foi ocupando espaços na esfera pública, uma vez que o homem já não dava conta do seu papel de provedor. Para a autora, tais fatores influenciaram no declínio do poder paterno. Sobre essa constatação, a Participante 3 refere: "As mudanças de lugar, de papel, as transformações de gerações, do que compete às gerações mais velhas ou às gerações mais novas, das hierarquias. Por exemplo: filho devia respeito ao pai, mas hoje em dia é o pai que deve respeito ao filho. Então os axiomas propostos tiveram uma transformação radicalíssima, principalmente nas formas de se estabelecer relações" (P3).

Com a necessidade de acompanhar e atender as novas demandas da figura feminina e da sociedade ocidental capitalista, os papéis familiares precisaram se adaptar, tornando-se mais flexíveis, apontando para a possibilidade concreta de relações de gênero mais democráticas (Araújo, 2005). O homem, especialmente, precisou rever suas habituais funções, como a de único provedor, figura de autoridade e pequena participação no cuidado dos filhos e da casa. O entrevistado 3 exemplifica: "O que é ser homem hoje em dia? O homem pode ter um papel de delicadeza com sua esposa, com sua namorada, com sua companheira. O pai pode se fragilizar, o pai pode cumprir funções que antes não eram designadas a ele. Houve a quebra de uma identidade hegemônica." (P3).

Constata-se o surgimento de novas demandas para o papel masculino. Staudt (2007) refere a chegada de um 'novo homem', mais participativo na vida afetiva e familiar, compartilhando com a mulher os âmbitos público e privado. Para a autora, os estereótipos de homem ligados à macheza, virilidade e força vêm sendo atualmente questionados. Contudo, o Participante 7 menciona que o homem parece ainda manter uma exigência de ser o 'chefe da família', o que implica uma subordinação por parte da esposa: “O homem ainda carrega culturalmente uma exigência, que eu percebo estar no inconsciente desses homens, da necessidade de ser o provedor, mas esse modelo pressuporia uma mulher submissa, o que está posto em cheque por ela" (P7).

Segundo Kehl (1996), frente à reivindicação de uma maior igualdade entre os sexos, a contemporaneidade acabou trazendo uma relativa indiscriminação entre os campos masculino e feminino, gerando desconforto e promovendo mais intolerância do que diálogo, bem como mais rivalidade do que desejo. A Participante 8 sugere que as mulheres estão se sentindo completas e autossuficientes: "A auto-ajuda, as revistas femininas e os tratamentos não tão bem sucedidos começaram a dar para as mulheres uma arrogância tamanha, de que elas não precisam de nada e de ninguém. E, para que mesmo, diante dessa arrogância feminina, serve um homem? Isso criou um descompasso, pois de uma utilidade extrema que os homens tinham para as mulheres e para a cultura, eles passaram a não ser mais úteis. A atual posição feminina não é equilibrada, mas sim é arrogante e narcisista!" (P8).

Na modernidade, de acordo com Kehl (2004), o asseguramento do valor fálico dos homens apoiava-se no seu valor em exercer as funções de marido e pai. Dessa maneira, as esposas e os filhos sustentavam a virilidade do homem. Nesse sentido, também, assinala Birmann (2006), que no contexto da família nuclear moderna se inscreveu uma divisão estrita de poderes paterno e materno, ou seja, "se a figura paterna se inscrevia no registro da governabilidade do espaço público, a figura materna se inscreveu no registro da governabilidade do espaço privado" (p.29). Entretanto, o contexto contemporâneo não apresenta o mesmo rigor nas configurações familiares. No que diz respeito ao posicionamento feminino ilustrado pela Participante 8, pode-se perceber o sofrimento implicado aos homens, já que essas transformações advindas do contexto social e cultural trazem profundas implicações nas escolhas e investimentos no campo intersubjetivo. São esses efeitos decorrentes da dinamicidade e singularidade dos fatores relacionados às novas prioridades na esfera da composição familiar que se fazem presentes na fala dos entrevistados: "Anteriormente as relações eram a prioridade, as relações familiares e as afetivas. A vida individual existia quando não atrapalhava a relação. Agora é ao contrário. A relação existe quando não atrapalha a vida individual" (P8). "As mulheres vêem cada vez mais comprometidas com sua vida profissional, com suas tarefas, com seus projetos de independência e tudo mais. Mas, também, isso acontece porque ela não encontra uma reciprocidade no seu par, e isso é um grande problema da formação da família contemporânea" (P2).

Denota-se, assim, como a contemporaneidade é marcada pelo privilégio da individualidade em detrimento das relações de alteridade. Birman (2007) refere um autocentramento do sujeito no eu, tornando o espaço intersubjetivo desinvestido e esvaziado de trocas inter-humanas. Para Lash (1990), o eu se contrai em um núcleo defensivo, a fim de evitar a ameaça provinda de uma época submersa em adversidades. As demandas contemporâneas impõem ao sujeito um alto nível de desempenho, a fim de obter acesso aos bens de consumo que prometem prazer e felicidade. $\mathrm{O}$ sucesso é considerado como a única alternativa de futuro viável, e, para conquistá-lo, tudo acaba sendo possível. O padrão que rege o contexto contemporâneo é o do gozo a qualquer preço (Maia, 2005). Nessa perspectiva, os vínculos afetivos são conduzidos pela mesma lógica. As relações precisam adaptar-se à necessidade de prazer contínuo, sendo o outro descartado, ao surgir alguma ameaça de sofrimento. Entretanto, os laços afetivos exigem tempo e continuidade de vinculação para que se estabeleça a confiança e a criação de relações de reciprocidade.

Desse modo, Lasch (1990) propõe que a contemporaneidade é marcada pela cultura do narcisismo, na qual a preocupação excessiva com a individualidade está diretamente associada com a própria sobrevivência psíquica, e não como manifestação de autointeresse ou de indiferença ao bem comum. Acrescido a isso, a época atual também pode ser caracterizada pela 'cultura dos não castrados', sustentada pela extremada imposição de ideais a serem seguidos, como mencionam as entrevistadas: "Existe uma ilusão na cultura atual, que é uma cultura de que a gente pode tudo.A gente tem acesso a tudo e a gente pode tudo. Em palavras estritamente psicanalíticas, é uma cultura de não castrados" (P8). "Esse sujeito, ao invés de traçar um ideal próprio, fica submetido ao ideal da cultura. Então é o ter, ter o carro tal, ter a marca tal. Como fica o compromisso do sujeito? O compromisso do sujeito é ter. Isso vai ficando desproporcional ao ser. Daqui a pouco, esse sujeito não sabe mais quem ele é, está psiquicamente comprometido no que ele tem que ter" $(\mathrm{P} 4)$.

Nesse panorama, o enfoque dado à castração remete a uma leitura na qual ela não se reduz à diferença anatômica 
entre os sexos, estritamente sobre a presença ou ausência de pênis, descrito por Freud (1909/2006). Segundo Hausen (2004), apesar de a castração aludir a um corte e a uma perda, ela também está imbuída da possibilidade de crescimento para o ser humano, pois demarca a saída do narcisismo e a entrada na fase do respeito e reconhecimento de um outro. Entretanto, ao relacionar a castração com a dinâmica dos tempos atuais, percebe-se um cenário de excessos no qual a não aceitação da falta impossibilita ao sujeito uma verdadeira experiência de alteridade. Nesse sentido, a 'cultura dos não castrados' alude à impossibilidade da inscrição da interdição no campo intersubjetivo, ou seja, o sujeito não pode sentir privação em relação à realização dos seus desejos. Para Dockhorn e Macedo (2008), na sociedade contemporânea o sujeito deve estar apto a aproveitar as oportunidades logo que estas se apresentarem, bem como seguir ininterruptamente desenvolvendo novos desejos. De acordo com as autoras, a dialética do desejo e da falta mostra-se inconsistente, pois não permite ao sujeito deparar-se com o vazio para despertar o desejo; ao contrário, o que ocorre é uma necessidade contínua de pôr fim à falta, instaurando novos objetos, produtos e falos que bloqueiam a alusão ao vazio.

Constata-se que, inegavelmente, novas formas de subjetivação surgiram com a contemporaneidade (Birman, 2007; Maia, 2005; Macedo, 2003; Bauman, 2001), e as modalidades impostas ao sujeito contam da complexidade dessas demandas referentes à identidade. $\mathrm{O}$ modo de vida advindo deste novo contexto, salienta Birman (2007), pode ser fonte de sofrimento pela exigência que imputa ao sujeito. No que se refere ao âmbito da masculinidade, percebe-se conflitivas relacionadas ao afrouxamento da cultura patriarcal, à transitoriedade das representações atribuídas ao falo, à preocupação com a manutenção da virilidade e à constituição da identidade. Tais fatores, para os psicanalistas entrevistados, estão diretamente relacionados às queixas e demandas apresentadas pelos homens na procura pela escuta psicanalítica.

No campo dessa temática, estrutura-se a segunda categoria final, chamada "O padecimento masculino contemporâneo: a história de Narciso no cenário de excessos". Ao abordar a temática dos padecimentos psíquicos, cabe esclarecer o que se entende por psicopatologia para a Psicanálise. Segundo Berlinck (2000), a palavra grega pathos deriva de sofrimento. Assim, quando pathos se faz presente no sujeito, isso significa que algo da ordem do excesso e da desmesura o acometeu de fora para dentro. $\mathrm{O}$ autor refere que o sujeito deve se assenhorar de pathos, de forma que esse deixe de ser transitório para o sujeito, ao transformar esse sofrimento em uma experiência que alargue e enriqueça o pensamento. A psicopatologia para a Psicanálise corresponde a uma experiência de conhecimento a respeito do si mesmo. Por meio dos relatos dos entrevistados, é possível perceber os efeitos psíquicos decorrentes das transformações contemporâneas em relação aos padecimentos masculinos: "Os homens estão apresentando problemáticas ligadas à inserção na sua própria identidade, de deixar para trás a questão narcisista e poder reconhecer seu lugar no mundo adulto, mesmo que sejam pessoas de 50 anos" (P3). "Transtorno de Identidade, a pessoa não sabe bem o que quer na vida, tem uns que não sabem nem se são crianças ou se são adultos. (...) a pessoa passa a sua vida procurando alguma coisa, sempre uma sensação de vazio" (P1).

Nesse sentido, cabe realizar uma reflexão entre os padecimentos psíquicos e a cultura na qual o paciente está inserido, devido à complexidade desta relação. Assim sendo, a Participante 4 refere: "A leitura da contemporaneidade é importante. (...) Ela não determina (...) não posso não inscrever na minha escuta a questão atual, a contemporaneidade. O que eu não posso argumentar é que esse sujeito está padecendo por causa do contemporâneo, por que senão, todas as pessoas teriam a mesma patologia se a questão fosse a contemporaneidade. A cultura é um elemento importante na escuta, mas ele não determina o padecimento do sujeito. Há uma articulação da organização da singularidade do sujeito com essa demanda externa. É aí que dá o conflito" (P4).

A partir dessa verbalização, é possível depreender o quanto o contexto é importante e se relaciona de forma não linear com o padecimento trazido pelo paciente, uma vez que o contexto não é capaz de, por si só, originar o conflito isoladamente. Nesse sentido, a escuta dos psicanalistas deve ser permeada, mas não determinada, pelo efeito dessas exigências impostas na contemporaneidade, bem como deve priorizar as configurações que a singularidade do sujeito adquire nesse processo. Bleichmar (2009) faz uma relevante contribuição a essa problemática ao afirmar que um dos problemas do futuro da Psicanálise está em identificar e separar "aqueles núcleos de verdade que permanecem através do tempo e que remetem a questões invariáveis da constituição psíquica dos modos de subjetividade que mudaram ao longo do tempo" (p.33). Trata-se de reconhecer que a produção de subjetividade é de ordem social, política e histórica e o constitutivo do psiquismo "dá conta de aspectos científicos da Psicanálise e que se sustentam com certa transcendência em relação aos distintos períodos históricos" (Bleichmar, 2009, p.33).

Atualmente tem-se uma realidade que se impõe intensamente, dificultando a organização dos processos psíquicos e, consequentemente, interferindo no processo de subjetivação. Birman (2007) complementa que não se pode falar em mal-estar sem que se aluda ao sujeito, já que o mal-estar sempre se inscreve no campo da subjetividade. Bleichmar (2007) afirma que a construção da subjetividade está atravessada pelos ordenamentos da sociedade em relação as formas de se viver para se estar inserido no mundo.

Nos tempos atuais, a idéia do espetáculo, com seus imperativos de exibição e teatralidade, promove que os sujeitos se insiram como personagens na cena social. Nesse sentido, o sujeito é regulado pela performatividade, compondo gestos voltados para a sedução e captura do outro (Birman, 2007). Entretanto, ao serem personagens, não há espaço para a demonstração de cenas verdadeiras que estejam em consonância com o que é real e singular de cada sujeito. Bauman (1998) considera que a imagem de si mesmo, como fazendo parte de uma construção identitária, perde seu lugar, pois passa a configurar como uma coleção de instantâneos, em que a função mais importante da memória se desloca do campo da lembrança para o do esquecimento.

O sujeito não consegue identificar-se com um padrão estável que lhe sustente a sua identidade, pois deve manter-se contingente às trocas de valores. Dessa forma, o sujeito, 
ao se distanciar do ser, cada vez mais confunde a imediatez com a identidade. Nesse contexto, insere-se a masculinidade. Ao fascinar o olhar do outro, o homem busca, nessa imagem, algo que o defina e dê contornos para o seu vazio identitário. O Participante 4 refere: "Tenho observado estas organizações mais narcisistas. As manifestações estão evidentemente em torno da sexualidade, da potência, das frustrações em relação aos ideais, isso é uma temática muito importante no masculino, os ideais, os projetos e a frustração em não ter podido alcançar isso" (P4).

É possível perceber o quanto o homem sente-se inseguro diante das transformações do contexto atual. Ao mesmo tempo em que lhe é exigida uma sensibilidade antes restrita, a possibilidade de sensibilizar-se parece amedrontadora. No que se refere aos atributos masculinos patriarcais, o homem segue mantendo uma representação de poder, pois a cultura ainda está arraigada por tais conceitos. Dessa forma, são as problemáticas ligadas a sua representação masculina tradicional, bem como as dificuldades relacionadas com ao desempenho que fazem o homem ocupar-se de suas questões subjetivas e buscar ajuda terapêutica. Nesse sentido, Costa-Júnior e Maia (2009) constatam que os homens assumem os cuidados com a saúde quando algo prejudica o status de virilidade, força e desempenho social. O homem, então, inseguro frente à mudança de paradigma e desestabilizado em relação ao novo papel da mulher, vê-se aprisionado na exigência da performance, do alto desempenho, da potência e do sucesso. Tais cobranças, autodirigidas, apresentam a finalidade de ser reconhecido e, a partir do olhar do outro, poder descobrir quem realmente é.

Seguindo as demandas impostas, o âmbito profissional passa a ter extrema importância para a constituição da identidade masculina. Por outro lado, as crises no sistema econômico e o conseqüente aumento no índice de desemprego trouxeram incertezas e dificuldades para o homem se reconhecer fora da esfera produtiva, acarretando sofrimento (Meler, 2000). Inserido em uma perspectiva capitalista contemporânea que preza pela produção constante, atrelada à possibilidade de ascensão social, o homem encontra no trabalho uma sustentação simbólica de cunho valorativo. Este aspecto está diretamente associado às modalidades tradicionais de cultura patriarcal falocêntrica, mantendo e sustentando um pressuposto de que, ao assumir os espaços públicos e desempenhar a função de provedor, o homem garantirá sua virilidade e identidade. Além desses fatores, o trabalho parece favorecer a aquisição do sentimento de autonomia nos pacientes homens, como referem o entrevistado: "Através do trabalho, o homem pode se desgrudar da família, pode dizer 'chega, não quero mais saber o que tu pensa a meu respeito, não quero mais ouvir o que tu tem a dizer'. Então isso é uma coisa que tem que ver com uma ruptura importante" (P6).

A ruptura citada, proporcionada pelo trabalho como recurso de acesso aos próprios ideais, diz respeito ao processo de desligamento da condição de se manter conectado ao narcisismo e ideais parentais. A Participante 4 ilustra tal afirmativa: "O que muitas vezes a gente observa na clínica é que esses ideais estão atravessados pelo narcisismo dos pais, pela demanda narcísica dos pais, então ficaram homens adultos sem saber na verdade qual era o seu objetivo como sujeito" (P4).
Segundo Hornstein (2008), o narcisismo é a fonte organizadora do psiquismo, constituindo o ego e a relação com os outros. A primeira acepção freudiana do narcisismo pode ser definida como um estado evolutivo dos investimentos libidinais no qual o eu se constitui como unidade (Freud, 1914/2004). Nesse processo de constituição da imagem de si mesmo é fundamental o papel desempenhado pelos investimentos realizados pelas figuras parentais.

Ao discorrer sobre investimentos necessários ao surgimento do ego, é fundamental considerar a função materna. Para Hornstein (1989), o bebê deve ser adequadamente narcisizado por sua mãe. O bebê passa a ser o ideal da mãe, sendo esta experiência vivenciada por um sentimento de completude. Porém, Freud (1914/2004) salienta que posteriormente deverá acontecer uma espécie de perturbação nessa relação. Trata-se da vivência da conflitiva edípica marcada pela entrada de um terceiro na díade entre a mãe e seu filho. O terceiro, como objeto de desejo da mãe, inaugura um campo de exclusão para a criança. Assim, é rompida uma situação na qual, por ser identificada com o ideal, a criança experiencia uma condição ilusória denominada por Freud (1914/2004) como ego ideal, ou seja, nela seu eu coincide com uma completude ilusória. Como efeito da saída dessa situação, ela se identifica com o idealizado, com um ideal de ego, no objetivo de readquirir a plenitude vivenciada no narcisismo primário (Hornstein,1989).

O narcisismo infantil perdido é deslocado para o ideal do ego, uma vez que o ego não está disposto a renunciar a uma satisfação já experimentada. Assim, ao longo do desenvolvimento, o sujeito deixaria para trás esse ideal narcísico infantil, mas aspiraria ao seu regresso, mediante a realização de metas ou ideais projetados em um tempo futuro. O ideal do eu configura-se como uma "instância da personalidade resultante da convergência do narcisismo (idealização do ego) e das identificações com os pais, com os seus substitutos e com os ideais coletivos (...) o ideal do ego constitui um modelo a que o sujeito procura conformar-se" (Laplanche $\&$ Pontalis, 2000, p. 222). Trata-se de uma instância que, ao apresentar um estado ideal a ser alcançado, também censura e observa incessantemente o ego, a fim de compará-lo com esse ideal. Nesse sentido, Hornstein (1989) identifica como característico do sujeito adulto o ideal do eu enquanto instância reguladora da autoestima de cada um, referindo-se aos valores internalizados pelo sujeito, decorrentes de sua história de vida singular. A autoestima seria o produto final daquilo que o eu pode cumprir em relação às exigências do ideal.

Ao referir as características da contemporaneidade Maia (2005) constata a impossibilidade de deslocamento do eu-ideal para um ideal de eu, na medida em que os ideais inexistem enquanto bens simbólicos, pois na sociedade do espetáculo, descrita por Debord (1997), o registro dominante é o da imagem de superfície, sem representação psíquica. Em relação a isso, as problemáticas associadas ao narcisismo nos pacientes homens são manifestadas pelos entrevistados:"Os homens se separam e buscam de uma forma muito intensa, se acharem. Se acharem como indivíduos, porque sempre foram indivíduos ligados a companheira como estiveram no passado ligados às figuras paternas" (P4). "Há uma necessidade de serem bons em tudo, principalmente pela questão de gênero, por serem homens. Existe uma busca de um ego ideal que é 
inatingível, e o ego fica muito aprisionado nisso" (P10). "O homem adulto, idoso e adolescente não se sente cumprindo com o que ele deveria ser, em síntese, não castrado. Para os homens, eles deveriam ter muito mais poder do que realmente tem" (P8).

Tais relatos denotam a necessidade da manutenção da fantasia onipotente, característica do narcisismo infantil no qual o ego identifica-se com a completude. Mesmo que surjam conflitos relacionados à sexualidade, problemáticas relacionadas ao Complexo de Édipo, percebe-se nesses homens que as exigências se dão no nível da performance sexual, do ideal no desempenho do ato em si, o que remete a uma demanda de uma fase anterior ao Édipo. Trata-se da constatação de um ideal masculino marcado com intensidade pela demanda de completude e uma alta exigência no desempenho.

Pode-se nomear, a partir das falas dos entrevistados, a dinâmica de padecimentos masculinos que contam as peripécias de Narciso num cenário de excessos que o atordoam e causam prejuízos nas relações consigo mesmo e com outros sujeitos. Acometido dessa modalidade contemporânea de pathos, o homem atual busca responder às demandas sem um tempo de reflexão sobre seu próprio campo de desejos. $\mathrm{Na}$ ilusão da ausência de limites, limita drasticamente a condição de ser e de acessar a singularidade de seu desejo. Associa-se a essa constatação as referências por parte dos entrevistados de que os homens explicitam a falta da figura parental que sirva como um modelo que facilite o acesso a masculinidade adulta. Neste aspecto, o papel do pai exerce importante função. Conforme Rosa (2008), ao aludir à teoria freudiana, a identidade sexual masculina se constitui no momento em que o menino estabelece a resolução do Complexo de Édipo, identificando-se com o pai que ofereceu provas de potência em relação à mãe, sendo este internalizado como ideal do eu. Assim, a concepção de virilidade se sustenta na identificação ao pai, tomado como ideal. Bleichmar (2007) considera que a constituição da identidade de gênero masculina é atravessada por um paradoxo: o menino precisa ser como o pai, enquanto potência e sexualidade, mas também necessita não ser como o pai, pois deve manter uma posição passiva diante deste, permitindo a apropriação de seus atributos. A autora destaca a relevância do processo identificatório ocorrer via predomínio do amor na relação do filho para com o pai. Entretanto, para Rosa (2008), a contemporaneidade é marcada pelo declínio ou inoperância da função paterna, o que traz consequências para a integração da posição sexual masculina por parte deste. Faz-se presente um questionamento sobre como se identificar com uma ausência. Este aspecto é trazido pelos entrevistados: "Há uma falta importante desse tipo de modelo masculino que vai desde pacientes que efetivamente perderam o pai e não conseguiram de alguma forma, na sua realidade, um modelo de função paterna, e de alguma maneira vem buscar isso na clínica, até adolescentes que sofrem com a separação dos seus pais e o pai passa a se omitir ou aumenta o seu grau de omissão" (P7). "Uma causa de sofrimento é a questão da indefinição, da indiferenciação, melhor dito, sobre a identidade de gênero. O quê é ser homem, o quê é ser uma mulher. Como não tiveram os próprios pais, a figura de mãe mulher, e figura de homem pai, (...) se relacionam com o seu companheiro buscando sanar a dúvida sobre o quê é ser homem, que não aprenderam com os seus pais" (P3).
A partir das falas, retrata-se como a ausência dos genitores, especialmente o paterno, resulta em sofrimento e confusão em relação à constituição da identidade masculina, além de um sentimento de desamparo e de desamor. Bleichmar (2007) refere que o homem necessita, simbolicamente, ter incorporado o pênis do pai, já que o falo representa a posse de todos os seus atributos masculinos. Para a autora, a virilidade é conquistada através de uma fantasia homossexual de incorporação por penetração. Assim, se o pai não cumpre essa função, o menino segue procurando um modelo masculino que o ofereça a virilidade.

De acordo com os entrevistados, os aspectos relacionados à ausência paterna na infância do menino também se associam às dificuldades encontradas nos pacientes homens em exercer seu papel de pai na atualidade. Há uma insegurança sobre como proceder ao gerar um filho, pois mesmo que desejem não repetir a ausência, acabam não encontrando um referencial a seguir. Segundo Souza e Benetti (2009), os pais contemporâneos transitam entre o modelo patriarcal, em que a figura masculina deve prover economicamente a família, e o novo modelo, em que o pai apresenta maior envolvimento afetivo com a esposa e os filhos. Contudo, as autoras referem que, apesar do conhecimento atual sobre a necessidade do envolvimento masculino com os filhos e com a família, o 'novo pai' não está correspondendo a essa demanda. Nessa direção, surgem as conflitivas familiares, especialmente as localizadas no âmbito conjugal, conforme refere a Participante 7: "E isso passa a interferir diretamente na questão da sexualidade, então a gente tem algumas disfunções sexuais em função dessa perda aparentemente desse papel, vamos dizer, do homem líder, do homem provedor. Então há toda uma exigência dessa mulher por vínculos que muitos homens por falta desse modelo, por terem vindo de um modelo mais arcaico, tiveram o seu inconsciente irrigado fundamentalmente pela percepção de pais com outra linha de pensamento ou de mães mais submissas, e na tentativa de reproduzir esse modelo isso acaba não funcionando, por força da não aceitação mais da mulher e aí começam as crises, que vão desde crises de angústia até de depressão" (P7).

Sobre os relacionamentos afetivos, Chaves (2003) considera que estes, na contemporaneidade, são apenas uma das tantas dimensões na vida de homens e mulheres. A autora menciona que as relações amorosas contemporâneas são caracterizadas pela diversão e pelo prazer imediato sem esforços. Nesse modelo de relação-lazer não há espaço para a hostilidade, tristeza, mal-estar e introspecção, que são aspectos intrínsecos a um relacionamento duradouro. Sendo assim, há uma tendência em usufruir das pessoas como objetos, e depois abandoná-las quando os impasses e frustrações aparecerem. A Participante 6 manifesta: "O motivo das separações é o de não haver contato afetivo, como se houvesse um certo desconhecimento do que é que o outro espera, do que o cônjuge esperava. O desejo do outro, a expectativa do outro, enfim, é como se esse outro estivesse ali, mas ao mesmo tempo não estivesse, porque é como se não tivesse contato, não se apropria desse outro" (P6).

Percebe-se mais uma vez como os efeitos do narcisismo se fazem presentes na cultura contemporânea, pelo prejuízo nos espaços intersubjetivos. Já, no que tange à dificuldade de investimento em si mesmo, encontram-se os padecimen- 
tos intrapsíquicos nomeados e identificados no cenário da masculinidade. Conforme Burin (2000), o imperativo social de adscrição ao gênero masculino leva os homens a um prematuro processo de socialização, bem como a recursos identificatórios e a modos de construção da subjetividade que os aleijariam da intimidade consigo mesmos. Nesse processo, os homens também acabam por se distanciar da percepção de certos desejos, principalmente os mais ligados à passividade, pois não condizem com a condição de virilidade. Do mesmo modo, a autora refere que os homens utilizam os mecanismos de negação, supressão e projeção de alguns afetos considerados difíceis de manejar subjetivamente, tais como o medo, a dor e a tristeza, já que o homem deve manter-se corajoso, forte e insensível. Essas características, associadas à construção da identidade de gênero tradicional, são consideradas como a 'normalidade masculina', mesmo que sejam potencialmente patógenas para o psiquismo (Burin, 2000). Nesse sentido, a autora faz alusão aos homens que padecem de normalidade. As verbalizações dos entrevistados 10 e 4 ilustram tal constatação: "Eles aprendem desde cedo que devem ser durões, machões, chefes tanto na família quanto no trabalho, enfim, não podem demonstrar muitos afetos. E isso não tem a ver só com o eu deles, mas também com o social, pois fica uma coisa muito impositiva, de terem sempre que ser muito bons em tudo" (P10). "Hoje até já está um pouco mais liberado para o homem chorar, mas o que predomina é não poder chorar, não pode falir, não pode falhar, não pode broxar, não pode nada. Só pode ter resultados! Então esse homem é uma figura massacrada de exigências. E aí ficou esse compromisso masculino.” (P4)

As falas dos entrevistados podem ser complementadas pela constatação de Berlinck e Fedida (1999), de que há nos homens uma tendência em defender-se, de maneira intensa, do reconhecimento da tristeza ou da depressão, pois a sociedade reprova tais manifestações. Assim sendo, cabe ressaltar a semelhança entre as características tradicionais da construção de gênero masculina e as demandas da sociedade contemporânea. Ambas exigem do homem prontidão, atividade, performance, negação da tristeza, exaltação do prazer, entre outras. Nessa configuração há uma importante contradição, pois na medida em que a autoestima é regulada pelo sentimento de satisfação e proximidade em relação aos ideais (Hornstein, 1989), e o contexto não oferece condições de realizar essa aproximação (Maia, 2005), se faz presente um paradoxo. Conseqüentemente, o sujeito pode padecer psiquicamente, mas como não lhe é permitido sentir a sua dor, ele acaba agindo a sua dor, seja na ausência de ação (depressões) ou na ação total (adições, impulsividades, compulsões). Contudo, Hornstein (2008) sustenta que muitos homens deprimidos não são diagnosticados, pois a atitude manifestada não consiste em retirar-se no silêncio do abatimento, mas sim refugiar-se e camuflar sua insatisfação e seu vazio no ruído da violência, no consumo de drogas ou na adição ao trabalho, caracterizando uma persistente irritabilidade. Sobre os motivos que levam um homem a se deprimir, Burin (2000) cita que a perda financeira é um dos maiores fatores de risco. Nessa direção, os entrevistados verbalizam: "A queixa geralmente é essa: não estou feliz. Claro, tem casos mais marcantes. A mulher que encaminha, a família que encaminha, porque está bebendo demais, porque está fazendo uso de drogas. Primeiro são transtornos depressivos" (P1). "Muitos homens acabam por terem dificuldades, de aceitar esse crescimento da mulher e se sentem com auto-estima abalada, porque a mulher passa a exigir desse homem fundamentalmente afeto e isso acaba, pelo menos com muitos homens que me procuram,por deixá-los muito angustiados" (P7).

Ao referir a situação econômica, Hornstein (2007) menciona que os desempregados estão sendo classificados como excluídos. Em uma sociedade ocidental que prima pelo consumo, o homem que não possui renda, ou que depende economicamente da outra pessoa, não só está excluído de um salário mensal, como também não é percebido, sendo tragado por uma rachadura social que ninguém quer chegar perto. Eles estão excluídos do olhar dos que estão, no momento, incluídos, provocando um colapso narcisista que traz a depressão como seqüela. Segundo Hornstein (2008), os deprimidos apresentam uma visão pessimista de si mesmos e do mundo, assim como um sentimento de impotência e fracasso, além de uma perda na capacidade de experimentar prazer. Nesse sentido, conforme a fala anterior do Participante 7, ao sentir-se desestabilizado em relação à nova posição da mulher, bem como ao experimentar sentimentos de angústia e depressão, o homem parece ser impedido de demonstrar o afeto que a parceira lhe exige. A economia afetiva, os investimentos pulsionais sofrem importantes abalos. A fim de se defender e garantir uma mínima sobrevivência psíquica, esse homem permanece autocentrado libidinalmente, prejudicando suas relações afetivas. No que se refere às questões da sexualidade, percebe-se a intrínseca associação dessa com a auto-estima, como menciona a Participante 8: "Uma mulher pode ter uma relação sexual não se sentindo tão inteira em termos de auto-estima. O homem, não. Porque uma relação sexual para um homem depende de uma ereção. E uma ereção tem a ver com uma auto-estima, de certa maneira regulada" (P8).

A constatação mencionada pela entrevistada 8 está relacionada aos emblemas da chamada 'sexualidade masculina normal' proposta por Meler (2000). A autora afirma que a obrigação de tomar a iniciativa para o ato sexual implica um grau de exposição ao rechaço, o que pode ocasionar sofrimento nos homens. Além disso, eles também temem a iniciativa feminina, pois os angustia a perspectiva de não cumprir com o desempenho esperado. O temor está sustentado pelo estereótipo de que, quando solicitados sexualmente, é proibido negar, já que sua masculinidade será questionada. A partir da angústia pela exigência da performance, percebe-se como o uso de drogas e álcool acaba sendo algo que alivia esses indivíduos. Segundo Hornstein (2008), o alcoolismo e as adições podem ser considerados como automedicação e costumam ser a outra face do vazio depressivo. No caso dos homens, percebe-se que este problema é agravado, na medida em que o álcool tem uma conotação positiva para a masculinidade, indicando força e resistência. Nesse sentido, Maia (2005) complementa que, na sociedade do consumo, há um ideário de prazer que em nada serve para saciar a necessidade de prazer do cidadão comum, o que gera um eterno estado de insatisfação. Assim, o adicto responde ao imperativo da sedação da dor por meio da busca do prazer imediato proporcionado pela droga. Na adição, busca-se narcisicamente lidar com a dor, alcançando um estado de plenitude primitivamente encontrado. Entretanto, rapidamente a euforia, a felicidade e 
o bem-estar encontrados de forma contingente se tornarão um compromisso imperioso. O entrevistado 2 refere: "Eu acho que se produz tantas alternativas da 'passage al act' que o homem não chega a perceber o sofrimento que deveras sofre, porque quando sofre tem uma possibilidade de atuar. Seja na ingestão excessiva alcoólica, que é um problema sério, seja no uso de outras drogas de abuso, seja cada vez mais no crack. É uma solução contemporânea para o sofrimento. Iimagina o risco que ela acarreta, ou pelo menos o tipo de problema que ela acarretará para o nosso trabalho. A impossibilidade de sofrer na presença de tanto sofrimento" (P2).

Sobre o mecanismo de passagem ao ato nomeado pelo entrevistado, Macedo (2006) afirma que esse ato expressa a impossibilidade de contenção de um excesso pelo recurso à representação simbólica. Assim, a incapacidade de atribuir uma representação psíquica ao conflito faz com que o ato seja o recurso predominante para esse psiquismo. Entretanto, segundo a autora, mesmo na ocorrência do ato como ato evacuatório, "o excesso (traumático) continua impondo ao psiquismo uma demanda de trabalho para o qual aquele não encontra recursos de mediação" (p. 234). Nesse sentido, o trabalho psicanalítico apresenta grande importância, pois oferece, na contramão das demandas contemporâneas, uma tentativa de reconhecimento, compreensão e elaboração do conflito. Quando os ditos 'recursos' da contemporaneidade para a resolução de problemas falham, retornando o sentimento de angústia, é ai que se busca o tratamento psicanalítico, conforme cita o Participante 2: "As pessoas, lançando mão desses recursos da contemporaneidade, esses recursos falham. Em algum momento eles falham. E nós trabalhamos na falha dessas soluções! (...) Todas as soluções da contemporaneidade, num certo sentido, são frágeis e superficiais" (P2).

Os entrevistados do estudo referem que os homens buscam atendimento na tentativa de compreender melhor seu sofrimento, pois muitas vezes nem sabem identificar o motivo pelo qual sofrem. Da mesma forma, os homens procuram atendimento psicanalítico para reconhecerem a si próprios, como exemplificam as verbalizações: "Os homens, pelo que parece, são freqüentemente levados ao tratamento por circunstâncias. Ou porque alguém quer que eles se tratem ou porque os sintomas colocaram eles perante uma impossibilidade, uma situação de rejeição, ou a mulher que quer se separar, ou fracasso profissional (...) perante um problema objetivo, ele é obrigado a se voltar para examinar os aspectos da sua subjetividade" (P9). "O que a gente tem que a gente procura dar? O auto-conhecimento. A pessoa conhecer, ter uma idéia, se apropriar da idéia dela como construtora do seu padecimento. (...) o alívio do seu sofrimento pela via do conhecimento de si mesmo, não por outras vias" (P5).

Apesar da inegável importância da compreensão de si mesmo oportunizada na clínica psicanalítica, bem como do alívio do sofrimento e do autoconhecimento como resultados alcançados, pode-se dizer que há uma leitura da psicopatologia na pós-modernidade que se caracteriza pelo paradigma biológico. Birman (2007) constata que as psicoterapias ficaram em segundo plano no campo da intervenção terapêutica, que se encontra centrada substancialmente nos psicofármacos. O autor refere que "a Psicanálise passa a ocupar um lugar secundário e periférico no discurso psicopatológico atual. Além disso, as intervenções assumem uma incidência pon- tual, baseando-se em disfuncionamentos em que o registro das histórias dos sujeitos é algo absolutamente secundário" (p.186). Entretanto, a Psicanálise pode contribuir na compreensão da complexidade predominante da atualidade ao dar destaque ao singular, gerando um espaço de atenção e cuidado no qual o intrapsíquico é valorizado e escutando a implicação do sujeito com seu sofrimento (Dockhorn \& Macedo, 2008). A Psicanálise, para Roudinesco (2000) "restaura a idéia de que o homem é livre por sua fala e de que seu destino não se restringe ao seu ser biológico" (p. 9). Para a autora, diante da dinâmica dos tempos atuais, principalmente no que se refere à valorização de uma competitividade desencadeada pela busca do sucesso profissional e material, muitos sujeitos acabam preferindo fazer uso de substâncias químicas que os anestesie frente aos padecimentos que lhes acomete ao invés de reconhecer sua magnitude e seus efeitos sob suas vidas. Assim, de acordo com os participantes deste estudo, o silêncio passa a ser preferível à linguagem, já que essa pode ser fonte de angústia e vergonha para o sujeito.

Diante do exposto, desenvolve-se a terceira categoria final, denominada "A vigência da Psicanálise como recurso ético na clínica contemporânea do masculino". Essa categoria ressalta a capacidade de escuta e o potencial terapêutico viabilizados na vigência da clínica psicanalítica. Os motivos de busca para um tratamento psicanalítico podem variar para quem o procura, mas a vivência da escuta do paciente por parte do psicanalista, seja pela palavra ou pelas manifestações de seu agir, possibilita-lhe atribuir significado às suas dores. Assim sendo, a Participante 4 refere: "Se um sujeito vem procurar uma análise, é porque ele pode ser analisado, senão ele não viria procurar. Então depende do analista poder ter uma escuta ética, e essa ética da escuta, não quero uma escuta pré-determinada, eu tenho que ouvir o quê que está trazendo esse sujeito. E o que vai trazer esse sujeito é a singularidade dele" (P4).

Conforme Macedo e Falcão (2005), a situação analítica é, por excelência, uma situação de comunicação, na qual circulam demandas que expressam o desejo e a necessidade de serem escutadas. A modalidade de escuta, oferecida pela Psicanálise, possibilita a compreensão do sofrimento humano a partir de dois trabalhos: o de escutar a palavra do outro e o de produzir palavras que venham ao encontro desse pedido de ajuda. O analista atua, dessa forma, como um decifrador, pois utiliza seus recursos técnicos para traduzir e revelar ao sujeito seus desejos. Nessa relação singular, estabelecida no encontro analítico, dão-se as condições para que o trabalho psíquico de tornar consciente o inconsciente aconteça. Longe de delegar um papel passivo ao paciente, a exigência de seu trabalho associativo o coloca, para Psicanálise, como centro desse processo de autoconhecimento, a partir da produção de sentidos singulares e pertinentes a sua história. A busca pela historização do sujeito torna-se imprescindível como forma de recuperar sua verdade histórica (Macedo \& Falcão, 2005). O profissional, mediante a sua implicação subjetiva, multiplica potencialidades e disponibilidades no trabalho analítico, pois produz uma caixa de ressonância para a escuta das demandas de seu paciente. Nessa lógica, cabe ressaltar a inserção do terapeuta no contexto contemporâneo, bem como o seu envolvimento subjetivo no processo analítico. $\mathrm{O}$ entrevistado 9 manifesta: "Evidentemente como psicanalista, 
também sou um produto desse meio. Sou produto desse meio que exige do homem sucesso, dinheiro, potência, representação social. Então, de certa forma, tecnicamenteme me incluo também dentro desse grupo e tenho que desenvolver uma escuta diferenciada para poder entender isto que é da ordem da sensibilidade masculina" (P9).

Denota-se, a partir da fala, a exigência de uma implicação ética por parte do profissional, enquanto sujeito que também se constituiu frente às mesmas demandas sociais e no mesmo contexto histórico. Porém, ao se reconhecer como sujeito de um contexto externo comum, o psicanalista não pode se furtar, em nome da manutenção de uma escuta ética, de levar em consideração as diferenças e complexidades presentes no processo de construção de um sujeito psíquico e, tampouco, as diferenças entre valores, projetos e metas que marcam a fecundidade e a autonomia desse encontro. Dessa maneira, evidencia-se a importância da capacidade interrogativa proposta por Freud, tornando a clínica como um espaço gerador de reformulações e acolhimento frente aos fenômenos humanos, priorizando a singularidade de uma história e prescindindo-se de pré-conceitos (Dockhorn \& Macedo, 2008). Para tal qualificação, é importante salientar o famoso tripé que cabe ao analista: a formação teórica, a atividade de supervisionar-se e a sua análise pessoal (Macedo \& Falcão, 2005).

Neste aspecto, Kupermann (2008) refere que qualidade do encontro afetivo que se estabelece entre analista e analisando conduz à criação de um estilo clínico baseado em uma ética do cuidado. Segundo o autor, o tratamento de pacientes com severas falhas em sua constituição narcísica oportuniza a estes a concretização de uma história com 'um novo começo', oferecendo condições para o preenchimento das primitivas lacunas que ficaram em aberto no psiquismo. Dessa forma, o analista é convocado em sua disponibilidade sensível para promover a produção de sentidos que é própria da experiência analítica. Ao abordar as especificidades da escuta na clínica psicanalítica, principalmente no que se refere à clientela masculina, o entrevistado 9 refere: "Vejo muito homens que tem uma transferência masculina, às vezes, um pouco assustados e preocupados em estar se sensibilizando junto a um analista homem" (P9).

É possível perceber o reconhecimento e a importância atribuídos à presença do processo transferencial nas falas dos entrevistados. Como sustenta Kupermann (2008), é no campo transferencial que o trabalho psíquico do analista exerce efeitos terapêuticos. Assim sendo, a transferência, no processo terapêutico, é um recurso fundamental, pois designa "o processo pelo qual os desejos inconscientes se atualizam sobre determinados objetos no quadro de um certo tipo de relação estabelecida com eles e, eminentemente, no quadro da relação analítica" (Laplanche \& Pontalis, 2000, p. 514). Segundo Freud (1917 [1916]/2006), a transferência deve ser devidamente manejada no campo analítico, com a finalidade de mostrar ao paciente que seus sentimentos demonstrados e aplicados à pessoa do analista não se originam da situação atual, mas sim que eles estão a serviço da repetição de algo ocorrido anteriormente na vida do paciente. Levar em consideração as demandas transferenciais exige do analista um conhecimento dos efeitos dessa demanda sobre si mesmo. $\mathrm{Ou}$ seja, como ilustra o Participante 2, não se trata de repetir no cenário da análise a imposição de outro tipo de demanda ao paciente, mas sim de propor um modelo distinto do que se faz presente na história de seu padecimento: "Rigorosamente a técnica ainda não mudou substancialmente, mas a reflexão sobre a contemporaneidade, sim. Não se pode pretender que essas reflexões sobre como se organiza o mundo contemporâneo se reflitam sobre esses detalhes da técnica clássica, que é mais respeitosa naquilo que a pessoa quer mudar em si mesma. Eu acho que trata-se sobretudo disso, o quê que cada um quer mudar a respeito de si mesmo, não do que eu quero mudar nela." (P2).

Enfatizando o trabalho analítico, Hornstein (2008) compara a atividade do paciente com a de um historiador, pois o sujeito tem que se remeter ao seu passado, apropriar-se dele e transformá-lo. A análise implica que analisado e analisando possam, juntos, oferecer um destino representacional e simbolizante para uma intensidade dolorosa que se encontrava destituída de sentido. Nessa direção, ressalta-se como a construção compartilhada, oportunizada no encontro analítico, proporciona um espaço de intimidade para o analisando.

Pode-se associar a reflexão sobre a dinâmica que marca o encontro analítico ao alerta de Bauman (2004) a respeito de relações difusas e vorazes que marcam a contemporaneidade. Para o autor, nessas modalidades de relação, "a distância não é obstáculo para se entrar em contato - mas entrar em contato não é obstáculo para se permanecer à parte" (p.82). Portanto, a clínica psicanalítica se mostra como um valioso recurso que, na contramão dessa demanda contemporânea, busca a constituição e a manutenção de relacionamentos afetivos ao oferecer um genuíno espaço de vinculação. Dessa forma, o Participante 5 faz alusão à possibilidade de recriar ou, até mesmo, de descobrir um espaço de investimento afetivo e de relações de alteridade com a devida profundidade: "É uma demanda por intimidade, o que o analista tem a oferecer é a intimidade. Existe uma pseudo-intimidade, ela está às avessas, porque todo o mundo tem a sua página no Orkut, os seus blogs, então parece que ali está toda a intimidade da pessoa. Quando o que era íntimo se tornou público, o que é íntimo onde é que ficou? Some. Então eu acho que a análise é um lugar também de descobrir ou talvez redescobrir um espaço de intimidade. E há uma tendência de se ter muitos contatos e relações superficiais, e uma perda da intimidade, do contato consigo mesmo e com o outro, pensado como alteridade, não meramente um reflexo de si mesmo, um espelhamento narcísico, eu acho que isso é o ouro para a Psicanálise" (P5).

Nesse sentido, percebe-se como a Psicanálise não pode permanecer estanque e rígida no tempo. Os diferentes modos de padecimento psíquico na atualidade têm representado um grande desafio para a Psicanálise, que não se estagnou diante de novas demandas, mostrando-se fecunda como um saber consistente para a compreensão dos fenômenos psíquicos e seus desdobramentos na existência e no padecimento de cada sujeito. Hornstein (2008), ao mencionar o legado freudiano, adverte que a técnica deve se adequar à singularidade do paciente. Assim, Dockhorn e Macedo (2008) complementam tal proposição ao afirmar que a Psicanálise, enquanto teoria e técnica, nunca estará acabada, pois exige constantes revisões e reformulações a fim de manter sua capacidade de questionar, refletir e analisar os fenômenos humanos. Dessa maneira, denota-se a importância da flexibilização da técnica 
e da continuidade de produção de conhecimento psicanalítico, conforme ilustram os entrevistados: "Meu encantamento com a Psicanálise é exatamente nesse legado psicanalítico que é uma teoria nunca acabada, uma teoria sempre possível de ser pensada. Ora, se teoricamente é possível sempre estar se pensando, clinicamente também. $\mathrm{O}$ que serve para esse paciente, não serve para outro. E isso não é não ter uma sustentação teórica, técnica. Mas eu tenho que escutar o sujeito na singularidade dele" (P4). "A questão da Psicanálise ser uma teoria muito viva. Eu acho que a Psicanálise precisa seguir como, desde a sua criação, sendo reescrita. Os pacientes que produzem conhecimento" (P3).

A Psicanálise, de acordo com as falas dos entrevistados, segue acompanhando os acontecimentos históricos, reformulando-se a partir das novas formas de constituição das subjetividades que aparecem na clínica. Como bem enfatiza Bleichmar (2007), aqueles que deixaram o legado psicanalítico tentaram o melhor para a época em que lhes coube viver, mas quem recebe esse legado deverá separar dela o que obstaculiza o pleno desenvolvimento psicanalítico. Assim sendo, a flexibilização do campo analítico oportunizou uma ampliação no seu acesso, bem como uma modificação na forma e nas modalidades de busca pelo tratamento. Os entrevistados verbalizam: "O terapeuta está sendo convidado a essa flexibilização, ou seja, qual é o melhor papel, ou qual é o papel que aquele homem vai conseguir ter, que mais agrada a ele ter, quais as concessões que são possíveis para ele fazer. E isso exige, então, uma flexibilização da escuta, uma flexibilização do "setting", no sentido de poder acompanhar essas diferentes exigências, sem esse engessamento das interpretações, dos entendimentos. Eu acho que esse é o grande desafio, a meu ver, do nosso papel atual em relação ao homem." (P7). "O homem tinha vergonha, uma sensação de fracasso se ele procurasse um terapeuta, um analista. Isso eu já não noto mais. Então eu posso dizer assim, a clientela em si, mudou. Eles vêm com naturalidade agora." (P1).

Nessa direção, os entrevistados são unânimes em ressaltar que, atualmente, os sujeitos do sexo masculino têm apresentado maior busca analítica no que se refere aos seus padecimentos psíquicos. Antigamente, os participantes destacaram que a clínica era basicamente constituída por pacientes mulheres, sendo a clientela masculina inserida em terapias de casal ou em terapias focais, como grupos de alcoólicos anônimos, por exemplo. Contudo, nos dias de hoje, os homens parecem não apresentar mais o receio que os impedia de buscar análise.

Apesar de a contemporaneidade tentar afastar a percepção de sofrimento, a Psicanálise segue vigente em sua capacidade de escutar a singularidade do sujeito e fazê-lo dar-se conta de seus processos psíquicos. Conforme explicita Macedo (2003), percebe-se a necessidade de não reduzir a importância de uma escuta diferenciada do padecimento psíquico "uma vez que o ser humano, atualmente, parece não ter tempo para si e passa, por isso, a maior parte da sua vida tentando distanciar-se, primeiro de si mesmo, para depois evitar, a qualquer custo, uma experiência de alteridade" (p. 174). Segundo a autora, tal situação denota um estado na qual o sujeito "precisa correr tanto que já não sabe se a pressa tem a ver com o que busca ou se está aprisionado na impossibilidade de parar por não saber o que encontrará ao olhar-se" (p.174). Tais constata- ções derivam de falas, como a da Participante 8: “A gente tem que através da clínica mostrar para cultura que talvez é muito dolorosa a castração, mas que a gente é muito mais tranqüilo castrado, do que não castrado. $\mathrm{O}$ atendimento das subjetividades contemporâneas permite que os psicanalistas possam revelar para as pessoas quais são as conseqüências de enfrentar os problemas que elas têm medo de enfrentar, que a cultura tem medo de enfrentar" (P8).

Dessa forma, o psicanalista contribui "para minorar o sofrimento restritivo daqueles que aceitam o convite de enveredar na experiência de produção de sentido compartilhado, facilitando a emergência de uma vida mais potente e criativa" (Kupermann, 2008, p. 11). No que se refere à masculinidade, a ética da Psicanálise se faz presente na medida em que se propõe a não impor um modelo a ser seguido pelo paciente, mas sim a abrir a possibilidade respeitosa de o homem se deparar com o que lhe faz sofrer e construir com este o modelo que lhe seja saudável. Logo, o compromisso ético dessa modalidade de escuta está em reconhecer o direito de o sujeito ser, efetivamente, o produtor de sentidos e rumos de sua vida. Por isso, situar-se na contramão das demandas de excesso da contemporaneidade confere à Psicanálise sua maior fonte de vigor.

\section{Considerações Finais}

Este estudo procurou abordar o padecimento psíquico masculino configurado no cenário contemporâneo. Para tanto, buscou-se o cenário da clínica psicanalítica, o qual contempla os enlaces que se dão entre as características dos tempos atuais e as modalidades de padecimento psíquico. Dessa forma, enfatiza-se a importância de dar atenção à subjetividade, compreendendo-a desde uma inserção numa cultura de excessos. Tal cultura pode propiciar o surgimento de certos tipos de padecimento psíquico, tendo em vista as características que esta contempla, mas o estudo realizado permite afirmar a impossibilidade e, também, a limitação de uma compreensão linear de causa e efeito entre as características de uma cultura e a produção de padecimento psíquico no cenário da masculinidade. Nesse sentido, não é porque o indivíduo está inserido em uma determinada cultura que ele irá adoecer psiquicamente.

A clínica psicanalítica se constitui, por excelência, como um espaço no qual adentra a singularidade de uma história, assim como nela se faz necessário o exercício ético de escutar o padecimento de alguém que, ao buscar o recurso da análise, se mostra disponível para refletir a respeito de sua história. Os entrevistados demonstram, por meio de suas falas, a importância de se estudar esses padecimentos e suas intrincadas relações com fenômenos tais como o narcisismo, a produção de ideais, a transferência, entre outros.

Resgata-se, neste estudo, a idéia de que o processo de subjetivação masculina não é, como erroneamente possa parecer, menos complexo do que o feminino. Não se trata, portanto, de compará-los, mas sim de enfatizar suas diferenças, bem como de apontar os aspectos que se interferem mutuamente.

Cabe ressaltar que o gênero masculino ao qual o estudo se refere pertence à sociedade ocidental, pois estudos referentes às sociedades orientais terão outra realidade no que tange 
à dinâmica da cultura e à bagagem de um tempo histórico. Além disso, ressalta-se o fato de que os profissionais entrevistados nesse estudo exercem uma clínica psicanalítica em cidades consideradas como grandes centros urbanos, ou em cidades muito próximas a eles, e têm como oriundos da classe média a maioria de seus analisandos. Dessa maneira, não se pretendeu universalizar a compreensão obtida nesse estudo, mas sim aprofundar o conhecimento acerca de sujeitos que buscam a escuta psicanalítica e, por meio dela, contam dos efeitos das diversas transformações que os acometem tanto no cenário intrapsíquico como em seus espaços intersubjetivos.

Nesse sentido, pensar nas modificações que a contemporaneidade produz e impõe ao sujeito, conduz a relevantes reflexões sobre suas implicações, assim como sobre a possibilidade de abordar o efeito do excesso frente ao processo masculino. A compreensão desta temática, à luz da escuta analítica, evidencia a importância do trabalho do analista no seu ofício de acesso às diferentes modalidades de padecimento psíquico. Na medida em que o encontro analítico visa atribuir sentido à dor psíquica, a clínica é um campo privilegiado de qualificação do processo de genuíno autoconhecimento.

Abordou-se nesse artigo o processo de escuta de analistas, considerando-se uma clínica com suas especificidades. Trata-se, portanto, de seguir investigando a dinâmica relação que se estabelece em outras condições sociais, econômicas e culturais quando se trata de refletir a respeito das demandas que levam um homem a buscar ajuda no cenário da clínica psicanalítica. Como a própria essência da teoria psicanalítica, este estudo retrata, também, a vigência saudável e necessária do aspecto mais genuíno do saber: sua incompletude.

\section{Referências}

Araújo, M. F. (2005). Diferença e igualdade nas relações de gênero: Revisitando o debate. Psicologia Clínica, 17(2), 41-52.

Bardin, L. (1991). Análise de conteúdo. Lisboa: Edições 70.

Bauman, Z. (1998). O mal-estar na pós-modernidade. Rio de Janeiro: Jorge Zahar.

Bauman, Z. (2001). Modernidade líquida. Rio de Janeiro: Jorge Zahar.

Bauman, Z. (2004). Amor líquido. Rio de Janeiro: Jorge Zahar.

Berlinck, M. T. (2000). Psicopatologia fundamental. São Paulo: Escuta.

Berlinck, M. T., \& Fédida, P. (1999). A clínica da depressão: Questões atuais. Revista Latinoamericana de Psicopatologia Fundamental, 3(2), 9-23.

Birman, J. (2006). Tatuando o desamparo. In M. R. Cardoso (Ed.), Adolescentes. São Paulo: Editora Escuta.

Birman, J. (2007). Mal-estar na atualidade: A psicanálise e as novas formas de subjetivação. (2rd ed). Rio de Janeiro: Civilização Brasileira.

Bleichmar, S. (2007). Paradojas de la sexualidad masculina. Buenos Aires: Paidós.

Bleichmar, S. (2009). El desmantelamiento de la subjetividadestallido del yo. Buenos Aires: Topía Editorial.

Burin, M. (2000). Atendiendo el malestar de los varones. In M. Burin, \& I. Meler. (Eds.), Varones: Género e subjetividad masculina (pp. 339-364). Buenos Aires: Paidós.
Ceccarelli, P. (1998). A masculinidade e seus avatares. Catharsis, 19(4), 10-11.

Chaves, J. (2003). Contextuais e pragmáticos: Os relacionamentos amorosos na pós-modernidade. Tese de Doutorado, Universidade Federal do Rio de Janeiro, Rio de Janeiro.

Costa-Júnior, F. M., \& Maia, A. C. B. (2009). Concepções de homens hospitalizados sobre a relação entre gênero e saúde. Psicologia: Teoria e Pesquisa, 25, 55-63.

Debord, G. (1997). A sociedade do espetáculo: Comentários sobre a sociedade do espetáculo. Rio de Janeiro: Contraponto.

Dockhorn, C., \& Macedo, M. (2008). A complexidade dos tempos atuais: reflexões psicanalíticas. Revista Argumento Psicologia, 54(26), 217-224.

Freud, S. (1909/2006). Análise de uma fobia em um menino de cinco anos. In J. Strachey (Ed. \& Trad.), Edição Standard das Obras Psicológicas Completas de Sigmund Freud (Vol. X pp.12-133). Rio de Janeiro: Imago.

Freud, S. (1914/2004). À guisa de introdução ao narcisismo. In L. Hanns (Ed. \& Trad.), Escritos sobre a psicologia do inconsciente (Vol. I pp.95-131). Rio de Janeiro: Imago.

Freud, S. (1917 [1916]/2006). Conferência XXVII: Transferência. In J. Strachey (Ed. \& Trad.), Edição Standard das Obras Psicológicas Completas de Sigmund Freud (Vol. XVI pp.433448). Rio de Janeiro: Imago.

Hausen, D. (2004). O trauma da castração: Sua origem / sua sorte. Revista do CEP de PA, 11, 69-88

Hornstein, L. (1989). Introdução à Psicanálise. São Paulo: Escuta.

Hornstein, L. (2007, setembro). ¿Acaso los hombres no lloran? La Nacion, Buenos Aires.

Hornstein, L. (2008). As depressões: Afetos e humores do viver. São Paulo: Via Lettera: Centro de Estudos psicanalíticos.

Jerusalinsky, A. (2007). Seminário V: O declínio do império patriarcal. São Paulo: USP, Pré-Escola Terapêutica Lugar de Vida.

Kehl, M. R. (1996). A mínima diferença: Masculino e feminino na cultura. Rio de Janeiro: Imago.

Kehl, M. R. (2004). A impostura do macho. Artigos e Ensaios. Jornada da Associação Psicanalítica de Porto Alegre. A Masculinidade. Retrieved from http://www. mariaritakehl.psc. br/ PDF/aimposturadomacho.pdf.

Kupermann, D. (2008). Presença Sensivel: cuidado e criação na clínica psicanalítica. Rio de Janeiro: Civilização Brasileira.

Laplanche, J., \& Pontalis, J. B. (2000). Vocabulário de Psicanálise (3rd Ed). São Paulo: Martins Fontes.

Lasch, C. (1990). O mínimo eu: Sobrevivência psíquica em tempos dificeis (5rd Ed). São Paulo: Editora Brasiliense.

Macedo, M. M. K. (2003). Uma leitura psicanalítica sobre o sofrimento na pós-modernidade. In P. Guareschi, A. Pizzinato, L. Krüger, \& M. Macedo (Eds.), Psicologia em Questão: reflexões sobre a contemporaneidade (pp. 163-175). Porto Alegre: EDIPUCRS.

Macedo, M. M. K (2006). Tentativa de suicídio: o traumático via ato-dor. Tese de Doutorado, Pontifícia Universidade Católica do Rio Grande do Sul, Porto Alegre.

Macedo, M. M. K., \& Falcão, C. N. B. (2005). A escuta na psicanálise e a psicanálise da escuta. Psychê, 9(15), 65-76.

Machado, F. (2008). Grupo de homens: repensando o papel masculino na sociedade contemporânea [Versão Eletrônica]. Pesquisa Psicológica: Revista Científica de Psicologia, 2(1), $1-31$. 
Maia, M. (2005). Extremos da alma: Dor e trauma na atualidade da clínica psicanalítica. ( $2^{\mathrm{a}} \mathrm{ed}$.) Rio de Janeiro: Garamond.

Meler, I. (2000). La sexualidad masculina. Um estudio psicoanalítico de género. In M. Burin, \& I. Meler (Eds.), Varones: Género e subjetividad masculina (pp. 149-198). Buenos Aires: Paidós.

Rosa, M. (2008). Ser um homem segundo a tradição? Fractal Revista de Psicologia, 20(2), 437-446.

Roudinesco, E. (2000). Por que a Psicanálise? Rio de Janeiro: Jorge Zahar.

Siqueira, M. J. T. (1997). A constituição da identidade masculina: Alguns pontos para discussão. Psicologia USP, 8(1), 113-130.

Souza, C. L. C.; Benetti, S. P. C. (2009). Paternidade contemporânea: Levantamento da produção acadêmica no período de 2000 a 2007. Paidéia, 19(42), 97-106.
Staudt, A. C. P. (2007). Novos tempos, novos pais? O ser pai na contemporaneidade. Dissertação de Mestrado, Pontifícia Universidade Católica do Rio Grande do Sul, Porto Alegre.

Recebido em 18.03.2010

Primeira decisão editorial em 17.06.2010

Versão final em 19.07.2010

Aceito em 24.08.2010 